\title{
Case Report \\ Rare Differential Diagnosis of Dyspnea: Extramedullary Plasmocytoma (EMP) of the Larynx-Case Report and Review of the Latest Literature of Laryngeal EMP and Laryngeal Involvement of Multiple Myeloma
}

\author{
Kim Vanessa Steinke $\mathbb{D}^{1},{ }^{1}$ Barbara Karoline Schneider, ${ }^{2}$ and Hans Jürgen Welkoborsky ${ }^{1}$ \\ ${ }^{1}$ Department of Otorhinolaryngology, Head and Neck Surgery, Nordstadt Clinic, Academic Hospital, Hanover, Germany \\ ${ }^{2}$ Department of Pathology, Nordstadt Clinic, Academic Hospital, Hanover, Germany \\ Correspondence should be addressed to Kim Vanessa Steinke; kim.v.steinke@gmx.de
}

Received 25 November 2018; Revised 28 February 2019; Accepted 13 March 2019; Published 17 April 2019

Academic Editor: Marco Berlucchi

Copyright (c) 2019 Kim Vanessa Steinke et al. This is an open access article distributed under the Creative Commons Attribution License, which permits unrestricted use, distribution, and reproduction in any medium, provided the original work is properly cited.

\begin{abstract}
Multiple myeloma (MM) of the larynx is extremely rare. It can be either a laryngeal manifestation of a general multiple myeloma or it can occur as a primary laryngeal mass, which is then called extramedullary plasmocytoma (EMP). We present the case of an 81-year-old male patient who was admitted for dyspnea. He had a history of multiple myeloma but was in complete remission since some years. Histological and immunohistological examination of tissue samples revealed an EMP. The patient was first treated by laser surgery in order to reduce the tumor mass and secure the airway. Afterwards, he was systematically treated by radiation therapy with $60 \mathrm{~Gy}$, which achieved a good response and complete remission proven by control laryngoscopy and histological examination of tissue samples taken from the former tumor area three months after laser excision. The latest literature in the field is reviewed. There were only ten cases of EMP in the larynx or laryngeal involvement of MM published within the last five years (Pubmed was searched for "larynx," "laryngeal" and "EMP," "Extramedullary Myeloma," "Multiple Myeloma," and "MM"). Due to its rarity, there are currently no evidence-based therapeutic guidelines available. For their development, multicenter studies are required.
\end{abstract}

\section{Introduction}

Multiple myeloma is a clonal malignant systemic disease of terminal differentiated B cells (plasma cells). The annual incidence in Germany is $4 / 100000$ [1]. It is characterized by accumulation and proliferation of $\mathrm{B}$ cells producing monoclonal immunoglobulin. Due to accumulation in the bone marrow, normal hematopoiesis is suppressed and the bone substance is destroyed [1].

These monoclonal plasma cells can also exclusively involve soft tissues, which is then called extramedullary plasmocytoma (EMP). 80-90\% of EMP is located in the head and neck which accounts for about $1 \%$ of all head and neck tumors [2]. The most affected sites are the oral and nasal cavity, the pharynx, the paranasal sinuses, and the larynx [3]. The main symptoms are due to local invasion of the tumor mass. Men are twice as often affected by EMP than women, whereas the 6th decade of life is the most probable time for disease occurrence [4-7]. Prognostic factors are uncertain [8].

Currently, only few cases of EMP located in the larynx or laryngeal involvement of MM have been reported in the international literature so far. Due to the rarity, to date consistent criteria for staging and treatment do not exist. This makes diagnosis and therapy challenging.

We here present a case of an extramedullary recurrence of a multiple myeloma involving exclusively the larynx.

\section{Case Report}

An 81-year-old male patient was referred to our department with dysphonia. There was no history of smoking. A status past multiple myeloma was known in his medical history 
that was in complete remission at the time of presentation. The patient denied dyspnea, dysphagia, pharyngalgia, and fever. Laryngoscopy revealed a diminished mobility of the right vocal cord and a thickening of the right vestibular fold so that a microlaryngoscopy with tissue sampling was performed. The histological examination of specimens obtained from this region revealed fibrosis. Computed tomography (CT) scans of the neck and the thorax were without any pathologic findings. The patient was discharged to outpatient care.

Three months later, the patient was admitted with progressive dyspnea along with inspiratory stridor. The clinical examination revealed now a complete paralysis of the right vocal cord and a remaining glottic cleft of only $1 \mathrm{~mm}$ due to a supraglottic protrusion of the right vestibular fold. The CT scan (Figure 1) showed now a tumor of the right vocal cord extending to the right piriform sinus.

After tumor debulking in order to expand and secure the airway, the excised material that consisted of several red brown elastic tissue fragments measuring together $24 \times 12 \times 10 \mathrm{~mm}$ was sent for pathological examination. Histologically, one could see tight lymphoid infiltrates. The cells had large nuclei and were irregularly shaped, and the proliferation was strongly enhanced in the staining for Ki67 (50\%). The immunohistochemical analyses showed a negative result for $\mathrm{CD} 20$ and $\mathrm{CD} 3$, and a positive staining for CD138. BCL2 and CD10 were coexpressed (Figure 2). The clonal light chain restriction for lambda chains substantiated the diagnosis of a multiple myeloma. These results were consistent with laryngeal involvement from the patient's previously diagnosed multiple myeloma.

The patient was referred to the Department of Hematology and a systemic therapy with the proteasome inhibitor Bortezomib was discussed. Ultimately, instead of that, a local radiation therapy with $60 \mathrm{~Gy}$ was performed. In a control laryngoscopy with tissue sample taken after the radiotherapy, the myeloma could not be verified anymore. The patient is in continuous otorhinolaryngological and oncologic follow-up. To date, almost two years later, no recurrence of the myeloma has occurred so far.

\section{Discussion}

The monoclonal terminally differentiated plasma cells of MM occur in the bone marrow as well as in soft tissues. Usually, patients with MM suffer from weakness, loss of weight, an increased susceptibility for infections, osteoporosis, pathologic fractures, hyperviscosity syndrome, or nephrotic syndrome [4-7]. The median age at diagnosis is $50-80$ years [9], and men are slightly predilected $[10,11]$. When only the extramedullary soft tissues are affected, the disease is called EMP. In $80 \%$ of cases, EMP involves the upper aerodigestive tract [11].

The laryngeal involvement is extremely rare and then can occur primarily as EMP (6-18\%) [12] or secondarily after medullary MM. The laryngeal infiltration of MM or EMP accounts for $0.04-0.19 \%$ of all laryngeal tumors [13]. Anatomical laryngeal sites which are mainly affected are the epiglottis, vocal cords, false vocal folds, aryepiglottic folds, and thyroid cartilage [3]. Main symptoms appear due to the local involvement and may include hoarseness, dyspnea, dysphagia, hemoptysis, and stridorous breathing. As EMP arises from the subepithelial layer, it is essential to take deep submucosal samples for histological examination in order to verify the diagnosis [3].

The histological examination is challenging because a clear delineation to other pathologies, i.e., chronic inflammatoric diseases or plasma cell enriched polyps as well as amyloid deposit, can be difficult $[14,15]$. Therefore, immunohistochemistry, flow cytometry, and immunophenotyping are crucial. Flow cytometry helps to characterize the cell population of the specimen by determining the cell size and the heterogeneity of the cells. Furthermore, by immunohistochemistry and fluorescence-activated cell sorting (FACS), it is possible to detect the expression of certain cell surface antigens (i.e., CD 38 and CD 138). These results help to prove the diagnosis of EMP [16].

Imaging techniques, i.e., computed tomography or magnetic resonance tomography, are helpful in order to clarify the local involvement of anatomical structures as well as to exclude further osseous and soft-tissue lesions and lymphadenopathy [17]. Typical findings for EMP in computed tomography imaging are calcification and areas with low densities in the thyroid cartilage and infiltrative growth pattern $[18,19]$.

Here, we have reviewed the latest literature. Ten cases of MM in the larynx or laryngeal EMP have been published in the last five years according to our Pubmed search [3, 8, 20-27]. The clinical and therapeutical findings are detailed in Table S1. In two of the ten cases, a MM had been known in the patient's history [3, 22]. In four of the remaining eight cases, the pathologic clinical findings in the larynx led to the diagnosis of MM [20, 21, 25, 26]. In one of the remaining four cases, additionally to the findings in the larynx, there was a solitary plasmacytoma of the rib [24]. There is no information provided concerning the follow-up of this patient. The three remaining cases can be regarded as solitary EMP $[8,23,27]$. In one of these three cases, the patient developed a MM three years and four months after diagnosis of EMP, which can be regarded as a progression from EMP to MM [27]. In one of the other cases, the diagnosis of isolated primary EMP in the process of dissemination was most appropriate [23] (Figure 3).

As far as therapy is concerned, it is the experience of the published cases in the last five years that the patients with preknown MM benefit from local treatment with radiation therapy and subsequent systemic therapy [3, 22]. Patients with newly diagnosed MM were systemically treated $[20,21]$, whereas in patients with EMP, surgery for local excision of tumor masses followed by radiotherapy was recommended $[8,23,27]$.

The treatment performed in the present case fits well in the series of similar cases in the literature.

The cases of the last five years show that there is no overall consensus regarding therapy for laryngeal EMP due to its rarity. There is some evidence that it is well treatable with radiotherapy with a good local control [23]. Alternatively local operative therapy, i.e., with $\mathrm{CO}_{2}$-laser excision in 


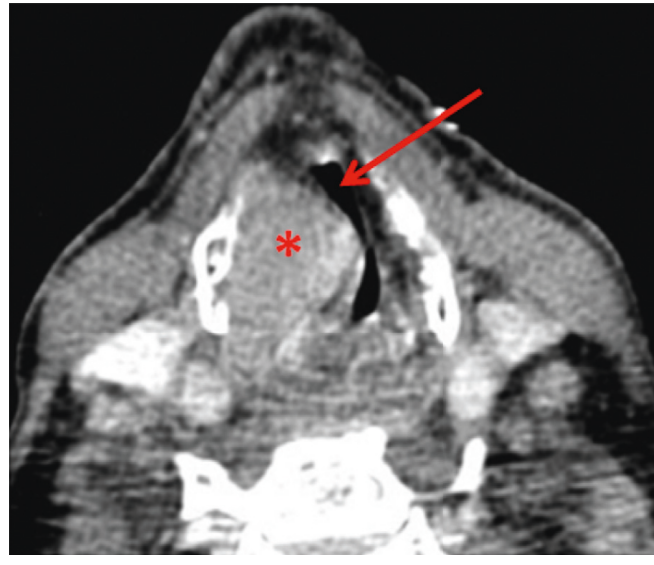

(a)

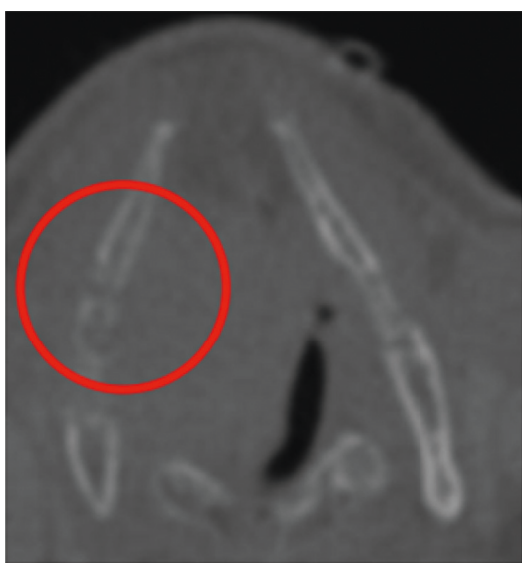

(b)

FIGURE 1: CT scan of the patient with the extramedullary multiple myeloma of the larynx. The tumor displays as a solid mass in the area of the right vocal cord (red asterisk). The lumen of the larynx and therefore also the airway is extremely narrowed (red arrow) (a). The thyroid cartilage on the right side seems to be significantly thinned out (red circle) (b).

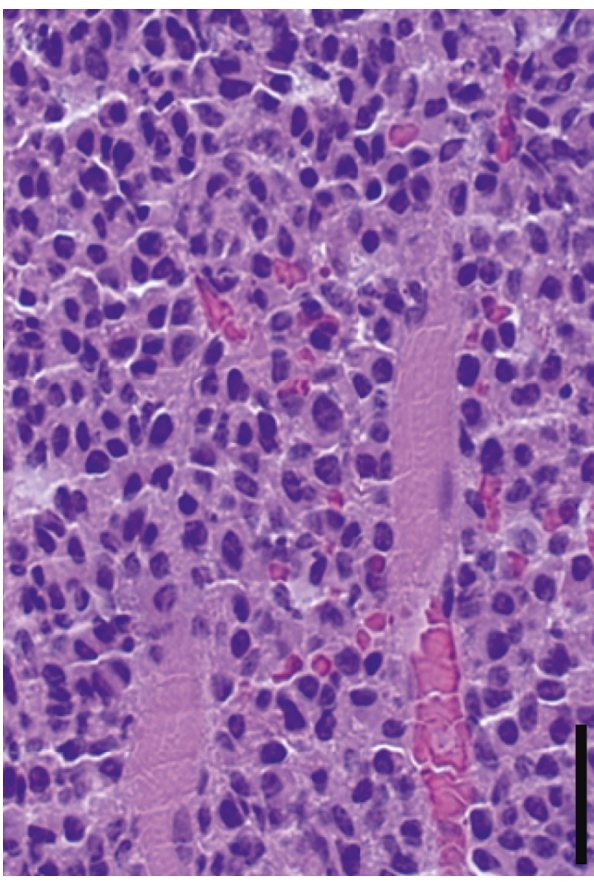

(a)

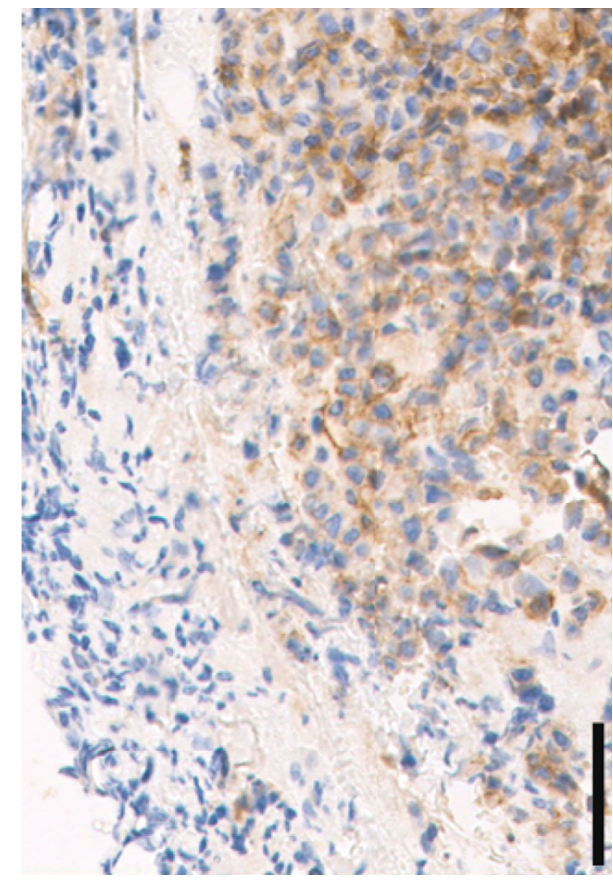

(b)

FIgURE 2: In HE staining, tight lymphoid infiltrates can be seen. The cells have large nuclei, and they are irregularly constructed (a). Immunohistochemical staining reveals a positive expression of CD10 (b). Magnification: 40x; scale bar: $50 \mu \mathrm{m}$.

combination with radiotherapy, might be appropriate $[8,27]$. The decision for the appropriate individual therapy should always be made in a multidisciplinary setting.

Autologous or allogenic stem cell transplantation is regarded as further alternatives to systemic therapy of $\mathrm{MM}$ [28]. As there is to date no cure of MM, a life-long oncologic follow-up is essential [29]. Reviewing the literature papers published on this issue possessed several limitations. Most of the papers contain case reports and no cohort studies. Furthermore, no uniformity could be found in the publications regarding the stage, grade, and outcomes, which makes a comparability of these reports difficult. Currently, no evidence-based therapy standards are available for extramedullary plasmocytoma [20]. Therefore, multicenter studies should be suitable and recommended to develop therapy guidelines.

\section{Conclusion}

In conclusion, EMP of the larynx or laryngeal involvement of $\mathrm{MM}$ is extremely rare. It should be taken under consideration in cases with subepithelial diseases of the larynx. 


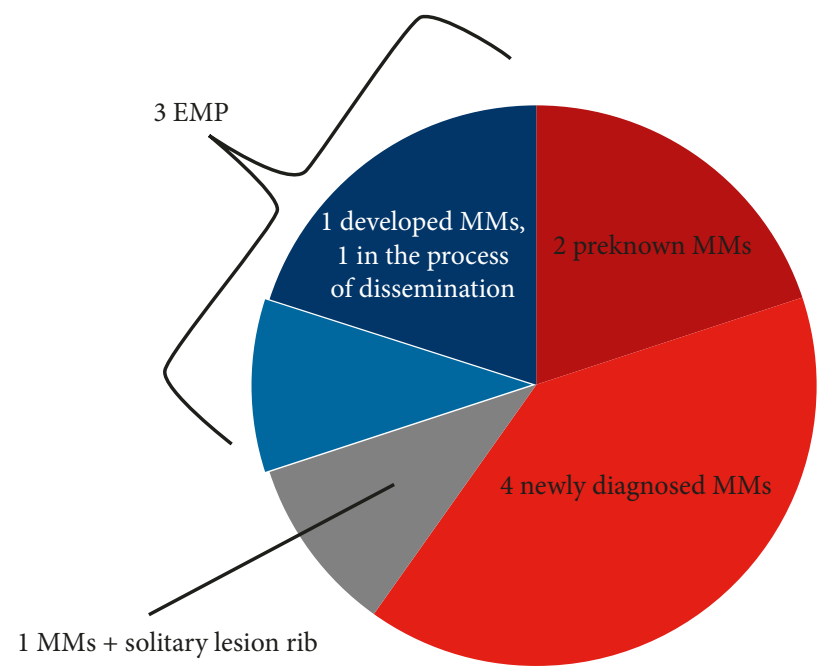

$\begin{array}{lc}\text { (i) Local radiotherapy } & \text { (i) Unknown } \\ \text { and peroral steroids } & \text { (i) Local operation, } \\ \text { vs. } & \text { radiotherapy } \\ \text { (ii) Local radiotherapy } & \text { recommended } \\ \text { and chemotherapy } & \text { (i) Local operation, } \\ \text { (i) Chemotherapy } & \text { radiotherapy } \\ \text { (ii) Dexamethasone iv, } & \text { (ii) Tracheostomy, } \\ \text { further therapy } & \text { radiotherapy } \\ \text { unknown } & \\ \text { (iii) Unknown } & \\ \text { (iv) Unknown } & \end{array}$

FIGURE 3: Pie chart of the distribution of MM and EMP and chosen therapy in the cases published in the literature during the past five years concerning laryngeal involvement by plasmocytoma $(n=10)$.

For histological examination, a deep and submucosal tissue sample is mandatory and diagnosis can only be made histologically and immunohistologically since urinary Bence Jones proteins or serum multiple myeloma protein can only be found occasionally [27].

\section{Ethical Approval}

All procedures performed in the study involving human participants were in accordance with the ethical standards of the institutional and/or national research committee and with the 1964 Helsinki Declaration and its later amendments or comparable ethical standards.

\section{Consent}

Informed consent was obtained from the individual participant included in the study.

\section{Disclosure}

Parts of this study have been presented as a poster at the Annual Meeting of the German Society of Otorhinolaryngology, Head and Neck Surgery ("Deutsche HNO-Gesellschaft"), Lübeck, Germany, May 10 to 12, 2018.

\section{Conflicts of Interest}

The authors have no conflicts of interest to declare.

\section{Authors' Contributions}

Kim Vanessa Steinke had full access to all the data in the study and takes responsibility for the integrity of the data and the accuracy of the data analysis.All authors contributed to this work.

\section{Supplementary Materials}

Table 1: overview of the cases of MM or EMP of the larynx published during the last five years [3, 8, 20-27]. The table shows age, sex, symptoms, anatomical site, treatment, response to therapy, and follow-up of the cases, if known. Besides, it is listed whether MM was preknown in the medical history of the patient. (Supplementary Materials)

\section{References}

[1] J. G. Meran, N. Zojer, and H. Ludwig, "Klinik, diagnose und prognose des multiplen myeloms," Der Onkologe, vol. 5, no. 4, pp. 297-306, 1999.

[2] B. Pichi, V. Terenzi, R. Covello, and G. Spriano, "Cricoidbased extramedullary plasmocytoma," Journal of Craniofacial Surgery, vol. 22, no. 6, pp. 2361-2363, 2011.

[3] H. K. Mitchell, G. Garas, N. Mazarakis, and J. McGlashan, "Extramedullary relapse of multiple myeloma in the thyroid cartilage," Case Report, vol. 2013, no. 30, Article ID bcr2013200689, 2013.

[4] N. A. Mayr, B.-C. Wen, D. H. Hussey et al., "The role of radiation therapy in the treatment of solitary plasmacytomas," Radiotherapy and Oncology, vol. 17, no. 4, pp. 293-303, 1990.

[5] J. L. Vigliotti, J. N. Myers, and S. B. Kapadia, "Extramedullary plasmacytoma of the larynx," American Journal of Otolaryngology, vol. 14, no. 2, pp. 128-131, 1993.

[6] S. E. Bush, D. R. Goffinet, and M. A. Bagshaw, "Extramedullary plasmacytoma of the head and neck," Radiology, vol. 140, no. 3, pp. 801-805, 1981.

[7] T. Nakashima, K. Matsuda, and A. Haruta, "Extramedullary plasmacytoma of the larynx," Auris Nasus Larynx, vol. 33, no. 2, pp. 219-222, 2006.

[8] Y. Xing, J. Qiu, M.-L. Zhou, S.-H. Zhou, Y.-Y. Bao, and Q.-Y. Wang, "Prognostic factors of laryngeal solitary extramedullary plasmacytoma: a case report and review of literature," International Journal of Clinical and Experimental Pathology, vol. 8, no. 3, pp. 2415-2435, 2015.

[9] P. R. Greipp, J. S. Miguel, B. G. M. Durie et al., "International staging system for multiple myeloma," Journal of Clinical Oncology, vol. 23, no. 15, pp. 3412-3420, 2005.

[10] R. O. Wein, P. Topf, and R. L. Sham, "Subglottic plasmacytoma: a case report and review of the literature," American Journal of Otolaryngology, vol. 23, no. 2, pp. 112-118, 2002.

[11] C. Alexiou, R. J. Kau, H. Dietzfelbinger, M. Kremer, J. C. Spiess, and B. Schratzenstaller, "Extramedullary plasmacytoma: tumor occurrence and therapeutic concepts," Cancer, vol. 85, no. 11, pp. 2305-2314, 1999. 
[12] Y. C. Nofsinger, N. Mirza, P. T. Rowan, D. Lanza, and G. Weinstein, "Head and neck manifestations of plasma cell neoplasms," The Laryngoscope, vol. 107, no. 6, pp. 741-746, 1997.

[13] K. Bjelkenkrantz, J. Lundgren, and J. Olofsson, "Extramedullary plasmacytoma of the larynx," Journal of Otolaryngology, vol. 10, no. 1, pp. 28-34, 1981.

[14] A. B. Grobman, R. J. Vivero, G. Campuzano-Zuluaga, P. Ganjei-Azar, and D. E. Rosow, "Laryngeal involvement of multiple myeloma," Case Reports in Oncological Medicine, vol. 2012, Article ID 257814, 3 pages, 2012.

[15] I. Aslan, H. Yenice, and N. Baserer, "An indolent course of multiple myeloma mimicking a solitary thyroid cartilage plasmacytoma," European Archives of Oto-Rhino-Laryngology, vol. 259, no. 2, pp. 84-86, 2002.

[16] I. Yavasoglu, G. Sargin, G. Kadikoylu, F. K. Doger, and Z. Bolaman, "Immunohistochemical evaluation of CD20 expression in patients with multiple myeloma," Revista Brasileira de Hematologia e Hemoterapia, vol. 37, no. 1, pp. 34-37, 2015.

[17] K. Lewis, R. Thomas, R. Grace, C. Moffat, G. Manjaly, and D. C. Howlett, "Extramedullary plasmacytomas of the larynx and parapharyngeal space: imaging and pathologic features," Ear, Nose, and Throat Journal, vol. 86, no. 9, pp. 567-569, 2007.

[18] T. Shimada, M. Matsui, K. Ikebuchi et al., "Multiple myeloma involving the thyroid cartilage," Auris Nasus Larynx, vol. 34, no. 2, pp. 277-279, 2007.

[19] J. Hisa, B. S. Slasky, O. Paltiel, G. Pizov, and E. Libson, "Multiple myeloma involving the thyroid cartilage: case report," American Journal of Neuroradiology (AJNR), vol. 23, no. 2, pp. 316-318, 2002.

[20] A. Z. Alherabi, A. M. Khan, O. A. Marglani, and T. A. Abdulfattah, "Multiple myeloma presenting as dysphagia," Saudi Medical Journal, vol. 34, no. 6, pp. 648-650, 2013.

[21] E. Allegra, N. Marino, D. Modica, C. Emmanuele, and V. Saita, "Primary laryngeal localization of multiple myeloma: a case report," Molecular and Clinical Oncology, vol. 6, no. 2, pp. 154-156, 2017.

[22] B. Floré and R. Hermans, "Multiple myeloma involving the cricoid cartilage," Journal of the Belgian Society of Radiology, vol. 96, no. 2, pp. 87-88, 2013.

[23] S. Ghatak, M. Dutta, I. Kundu, and R. P. Ganguly, "Primary solitary extramedullary plasmacytoma involving the true vocal cords in a pregnant woman," Tumori, vol. 99, no. 1, 2013, http://www.tumorionline.it/articoli.php?archivio=yes\&vol_ id $=1248 \&$ id $=13805$.

[24] G. C. Haser, H. K. Su, M. J. Pitman, and A. S. Khorsandi, "Extramedullary plasmacytoma of the cricoid cartilage with solitary plasmacytoma of the rib," American Journal of Otolaryngology, vol. 36, no. 4, pp. 598-600, 2015.

[25] S. K. Nochikattil, E. M. Iype, S. K. Ramrao, P. Nair, and S. Thomas, "A case of multiple myeloma: mimicking carcinoma larynx," Indian Journal of Otolaryngology and Head \& Neck Surgery, vol. 68, no. 4, pp. 534-536, 2016.

[26] A. Oral, B. Yazici, Ö. Ömür, M. Comert, and G. Saydam, "18FFDG and 18F-NaF PET/CT findings of a multiple myeloma patient with thyroid cartilage involvement," Clinical Nuclear Medicine, vol. 40, no. 11, pp. 873-876, 2015.

[27] M. Wang, J. Du, J. Zou, and S. Liu, "Extramedullary plasmacytoma of the cricoid cartilage progressing to multiple myeloma: a case report," Oncology Letters, vol. 9, no. 4, pp. 1764-1766, 2015.
[28] S. L. Yohe, "Classification of plasma cell neoplasms," in Plasma Cell Neoplasms, M. A. Linden and R. W. McKenna, Eds., Springer International Publishing, Cham, Switzerland, 2016, http://link.springer.com/10.1007/978-3-319-10918-3_4.

[29] V. Ravo, M. G. Calvanese, R. Manzo et al., "Solitary plasmacytoma of the larynx treated with radiotherapy: a case report," Tumori, vol. 98, no. 2, pp. 35e-38e, 2012, http://www. tumorionline.it/articoli.php?archivio=yes\&vol_id=1088\&id=11945. 


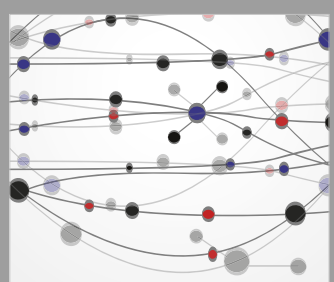

The Scientific World Journal
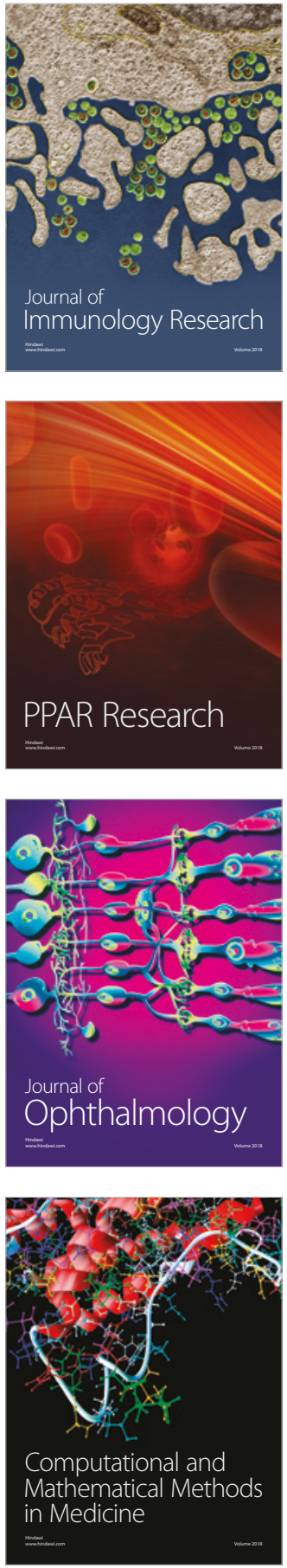

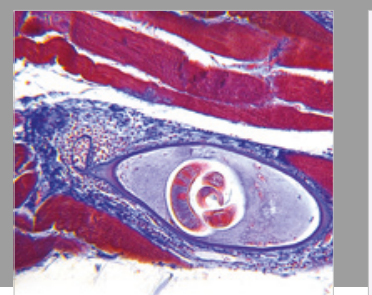

Gastroenterology Research and Practice

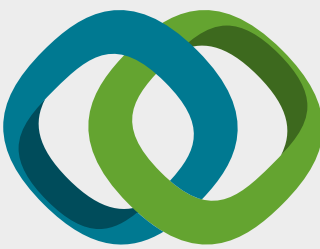

\section{Hindawi}

Submit your manuscripts at

www.hindawi.com
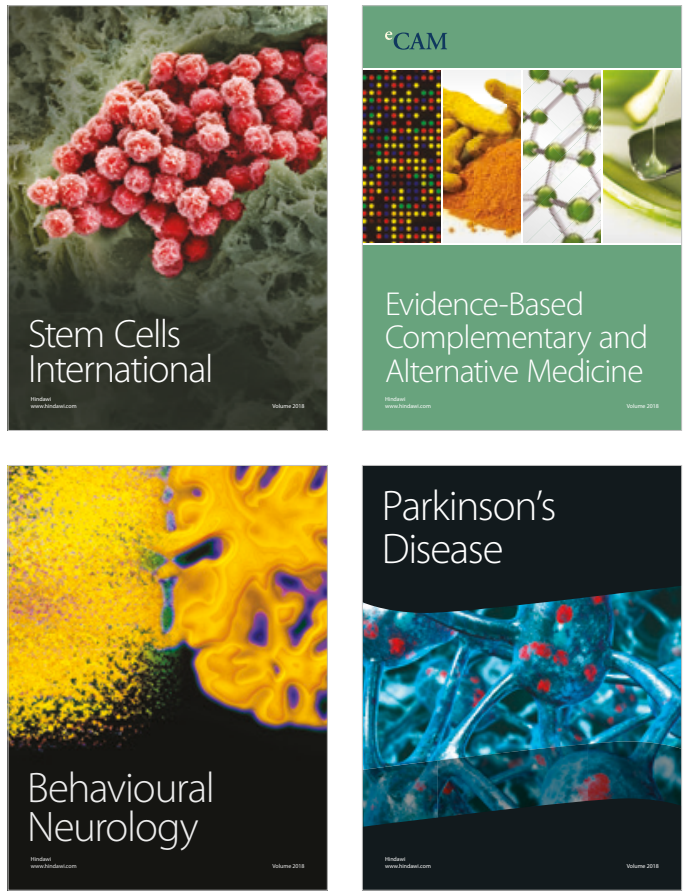

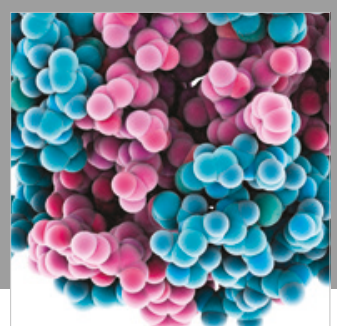

ournal of

Diabetes Research

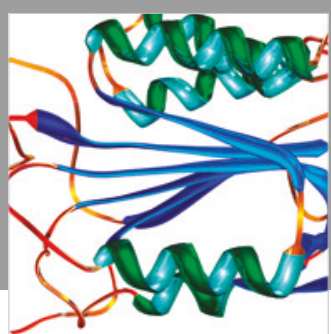

Disease Markers
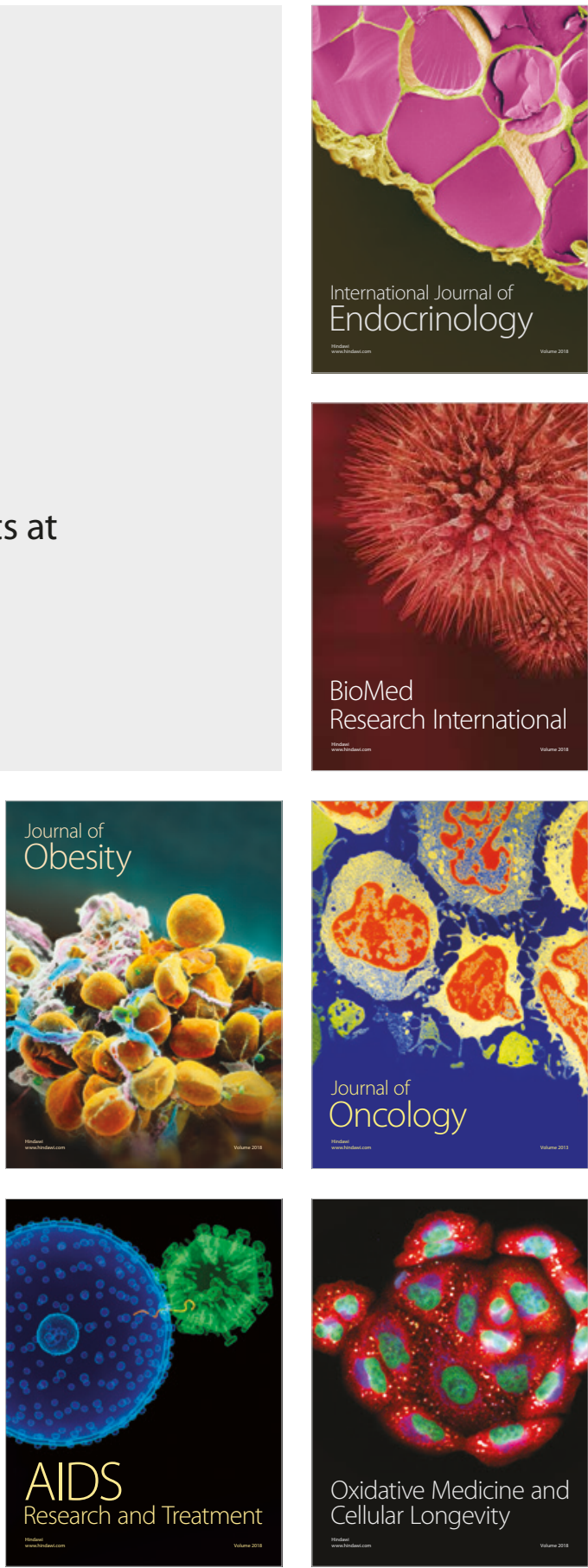